\title{
"Sin clientes no hay trata»: Genealogía, evidencia empírica e implicaciones
}

\author{
«No customers there is no trafficking»: Genealogy, empirical evidence \\ and implications
}

\author{
Paula Sánchez Perera \\ Doctora en Humanidades, área de Filosofía (UC3M) \\ Colaboradora del Colectivo de Prostitutas de Sevilla (CPS) \\ Paula.sanchezperera@gmail.com
}

Resumen

En el presente ensayo se discute el aforismo "sin clientes no hay trata» que defiende un amplio sector del movimiento por la abolición del comercio sexual. En una primera parte, se abordará la genealogía del discurso abolicionista en torno a la trata de personas, dando cuenta de los diferentes episodios que contribuyeron a estabilizar la interpretación dominante de la cual parte este razonamiento. En la segunda parte, se analizará la evidencia empírica que la sustenta, que se fundamenta en el modelo neoabolicionista implantado en Suecia a comienzos de este siglo. Finalmente, en la tercera parte se argumentará, a través de los desarrollos de la criminología crítica, que dicho razonamiento se haya comprometido con una serie de racionalidades de corte neoliberal y punitivista.

Palabras clave: modelo nórdico, comercio sexual, criminalización, trata de personas, prostitución.

\section{Abstract}

This essay discusses the aphorism "without clients, there is no trafficking" that is defended by a wide sector of the movement for the abolition of the sexual commerce. In the first part, we will approach the genealogy of the abolitionist discourse around human trafficking, going through the different episodes that contributed to stabilizing the dominant interpretation of this reasoning. In the second part, we will analyze the empirical evidence that supports it, which is based on the neo-abolitionist model that was implanted in Sweden at the beginning of this century. Finally, in the third part, it will be argued, through the developments of critical criminology, that this argument will be of neoliberal and punitive rationalities.

Key words: Nordic model, sexual commerce, criminalization, human trafficking, prostitution. 


\section{Introducción}

Uno de los principios axiales del abolicionismo de la prostitución se condensa en la oración: 'sin clientes no hay trata'. El desarrollo de este lema abolicionista lo encontramos, por ejemplo, en una Propuesta No de Ley registrada en 2018 por el Partido Socialista Obrero Español:

"El abordaje de la trata con fines de explotación sexual, por tanto, no puede desligarse del fenómeno de la prostitución, porque es la demanda de prostitución la principal causa del aumento de la trata de mujeres y niñas. La trata de mujeres y niñas para la explotación sexual existe porque hay hombres que demandan prostitución" (BOCG, 2018:53)

En virtud de la relación de causalidad directa que predica, el argumento establece que prostitución y trata son fenómenos indisociables. En consecuencia, mantiene que la vía más efectiva para erradicar la trata de personas consiste en la sanción de la demanda de la prostitución. En las siguientes páginas de este ensayo discutiré tal afirmación desde el análisis genealógico (1), empírico (2) y el de algunas de sus implicaciones ético-políticas (3)

\section{Genealogía de un discurso: del mito de la trata de blancas a la herida sexual}

La concepción positivista considera a la trata de personas un hecho dado y, en consecuencia, se centra en la documentación y descripción del fenómeno. Frente a esta caracterización se encuentra el enfoque discursivo, el cual se interroga por cómo se interpreta ese hecho y por cómo se construye la definición legítima (Doezema, 2005). Por tanto, resulta fundamental distinguir entre la realidad de la trata -indiscutible- y el discurso o la interpretación canónica de ese hecho -construcción humana-. En esta distinción anida una de las claves epistemológicas que permiten desentrañar tanto las bases del debate actual en torno a la prostitución como las derivas del feminismo en los escenarios supranacionales y trasnacionales. A este discurso sobre la trata Doezema $(1999 ; 2002)$ lo califica de mito, lo cual no supone negar la trata o considerarla un hecho falso, sino, de nuevo, atender hacia cómo esta se interpreta. Siguiendo la acepción que recoge esta autora, los mitos configuran una creencia colectiva que simplifica la realidad (Grittner, 1990) a través de una narración moral y dicotómica de víctimas frente a villanos. Este relato arrastra significados ideológicos con los que oculta las ansiedades sociales subyacentes que canaliza. De acuerdo con la idea foucaultiana de que todo acto de saber es también un acto de poder, Doezema ahonda en la dimensión ideológica que instala su significado a través de la reiteración del discurso. Ahora bien, deberemos evitar pensar en la noción de ideología desde la polarización habitual entre verdad/falsedad, como si hubiera unas ideólogas defendiendo un relato falso que debemos destapar para acceder a la verdad. En rigor, 'ideología' no apareja un sentido necesariamente negativo, ni supone que quien defienda un discurso alternativo para interpretar el hecho en cuestión posea la verdad o se encuentre exenta de ideología. Siguiendo a Doezema, una mirada genealógica nos permitirá ubicar los diferentes episodios que produjeron la estabilización de la definición dominante, que es también responsable de que cualquier intento por discutir su sentido se juzgue como 'negacionismo' de la trata.

Doezema $(1999 ; 2002)$ comienza por advertir los elementos discursivos que la interpretación contemporánea de la trata conserva del relato sobre la trata de blancas de finales del siglo XIX. EI fenómeno de la trata de blancas se narró a partir de historias de niñas y mujeres europeas que eran secuestradas, drogadas o engañadas para después desplazarlas al continente americano donde se 
les obligaba a ejercer la prostitución. Sin embargo, los historiadores que han investigado este fenómeno coinciden en que los casos documentados que se corresponden con este relato fueron escasos y sobredimensionados, y consideran que se trató de un incremento de la migración de prostitutas europeas en busca de trabajo en Latinoamérica y Estados Unidos (Connelly, 1980; Walkowitz, 1980; Corbin, 1990; Guy, 1992; entre otros). Tildar al fenómeno como 'esclavitud blanca' contraía evidentes ideas racistas -ya que era 'la blanca' la que se consideraba intolerable-, pero también antisemitas, pues los tratantes fueron descritos como judíos (Bristow, 1982:34). Como telón de fondo, el mito canalizaba ansiedades sociales: la pérdida del honor y la devaluación de su identidad europea, amenazada por las presumibles relaciones sexuales interraciales; y la batalla entre las normas morales protestantes frente a las católicas (Juliano, 2002:118). Puesto que en el orden patriarcal la mujer representa simbólicamente al colectivo (sea el honor de la familia, la nación o, incluso, la raza) y, a su vez, la virtud femenina evalúa su comportamiento sexual, el orgullo europeo herido se suturó convirtiendo a las migrantes en esclavas ${ }^{i 1}$.

Si Doezema (1999; 2002) describe el discurso actual sobre la trata como una reactivación contemporánea del mito de la trata de blancas es porque comparten una serie de rasgos, que continúan replicándose: la inflación de cifras; la conceptualización del peligro vinculado a la migración con implicaciones racistas y colonialistas; la mezcla y asociación entre mujeres y niñas; y el peso dado a la inocencia sexual como factor que activa tanto la compasión como la protección internacional. Sin embargo, ¿por qué tras el paso de los siglos se mantuvieron estos elementos?

Alice Miller (2004) ha documentado, como activista que entonces jugó un papel clave, el proceso que tuvo como objetivo situar en la agenda internacional los derechos de las mujeres como derechos humanos. Antes de la década de los 90, estas demandas eran consideradas temas de mujeres y se valoraba que su abordaje le competía al derecho penal interno de cada Estado. Llegadas a esta década, la práctica dominante, que ejemplificaba Amnistía Internacional, empleaba la tortura en conflictos armados como el paradigma de violación de derechos humanos. De esta manera, se estableció un enclave discursivo que reconocía como legítimas las demandas de vulneración de derechos a partir del daño al cuerpo. Esta fue la razón de fondo que llevase a los grupos de presión feministas a escoger el camino más corto para que se reconocieran los derechos humanos de las mujeres; los tematizaron a partir de la violencia y, concretamente, de la violencia sexual. Como alega Miller, podían haber incidido, en cambio, en cuestiones de justicia redistributiva o en las condiciones que merman la participación de las mujeres y limitan su agencia o, incluso, en las garantías para migrar de manera segura. No obstante: «Logramos más rápidamente atraer la atención del público en general respecto a un problema si este se conecta con las creencias existentes -incluidos los estereotipos de género, raciales y culturales- y no los desafía» (Miller, 2004:40).

La prioridad dada a la violencia sexual permitió que las violaciones de derechos contra las mujeres, como la trata, fueran consideradas vulneraciones de derechos humanos. Sin embargo, no fue una conquista exenta de consecuencias indeseadas. De un lado, este paradigma interpretativo reforzó el imaginario patriarcal ${ }^{2}$ que ubica en el sexo el mayor peligro (Vance, 1989) para el género

\footnotetext{
${ }^{1}$ Guy (1992:24) documenta cómo en el caso argentino las prostitutas nacionales no gozaron de la misma consideración ni fueron conceptualizadas como esclavas.

${ }^{2}$ En virtud de la primacía dispensada a la idea de inocencia sexual, se asocian mujeres y niñas (Doezema, 2004), menores que prevalecen en el imaginario incluso por encima de los varones que se prostituyen-y se mistifican la institución familiar y el hogar. Piscitelli (2015) documenta cómo las campañas contra la trata en Brasil se focalizan en difundir los riesgos que entraña 'salir de casa'. Esta purificación del hogar recrea la división entre espacio público y privado de manera generizada redefiniendo la geografía del peligro: en casa, sana y salva (Guy, 1992; Yuval-Davis, 1997).
}

Revista del Laboratorio Iberoamericano para el Estudio Sociohistórico de las Sexualidades https://doi.org/10.46661/5020 
femenino. De otro, la narrativa de la violencia sexual como lente interpretativa predilecta para representar la trata invisibiliza al resto de fines de explotación hacia las cuales se orienta, que quedan en un infranqueable segundo plano. De acuerdo con Rubin (2011:76): «para el público en general, 'trata' probablemente evoca muchas más imágenes de burdeles que de fábricas, granjas o casas particulares». El peso otorgado a la violencia sexual obstaculizó politizar otros enclaves, como las condiciones estructurales que dan lugar a la explotación laboral en régimen de servidumbre, comunes a todas las formas de trata.

El informe de la Organización Internacional del Trabajo de 2012 documentaba que el 68\% de la trata tiene como finalidad la explotación laboral, frente al 22\% sexual (OIT, 2012:1). Incluso el Departamento de Estado de los Estados Unidos apuntaba hacia esta dirección señalando: «la mayor parte de la trata de personas en el mundo toma la forma de trata laboral» (USDS, 2010:8). La trata laboral procedente de los talleres textiles o de los campos agrícolas, de la ropa que vestimos y la comida que consumimos, no conmueve tanto ni insta a campañas y acciones políticas que criminalicen a los consumidores. A su vez, la trata con fines de prostitución forzada no es la única forma de trata atravesada por el género, también lo son los matrimonios forzados y la dirigida hacia el sector doméstico, entre otras. ¿Por qué, sin embargo, no existe un movimiento organizado por la abolición del matrimonio y del trabajo doméstico en el mismo rango y fuerza que el de la prostitución?

En España, de acuerdo con el último balance del Centro de Inteligencia contra el Terrorismo y el Crimen Organizado (CITCO, 2018), la trata laboral y la sexual alcanzan cifras paralelas. Sin embargo, tanto la primera fase del Plan Integral contra la trata (2008-2011) como su ulterior (2012-2018) se centraron en exclusiva en la prostitución forzada y en ellos se asevera que la trata tiene como causa la prostitución. Contra este enfoque ideológico se pronuncia la última evaluación sobre los esfuerzos españoles por combatir la trata del Consejo de Europa (GRETA, 2018), el cual denuncia que la trata laboral en nuestro país se encuentra infrarrepresentada, escasamente detectada y sin protocolos específicos ni suficientes medidas de actuación. De este modo, el compromiso institucional con los principios del abolicionismo colabora de manera tácita con la falta de atención y de voluntad política para combatir las restantes formas de trata. De lo contrario, no podrían mantener que prostitución y trata son una y la misma cosa, pues esta afirmación se revelaría como una construcción ideológica.

\subsection{Los debates de Palermo}

El siguiente de nuestros episodios clave para entender la estabilización del concepto 'trata' nos sitúa en el plano supranacional de las Naciones Unidas durante los debates que se dieron para consensuar los Protocolos de Palermo y, en concreto, el relativo al año 2000, (Convenio Para Prevenir, Reprimir y Sancionar la trata de personas). Los dos lobbies en lucha, el abolicionista, capitaneado por la Coalition Against Trafficking in Women (CATW), y el proderechos, que se reunió en una coalición denominada Human Rights Caucus $(\mathrm{HRC})^{3}$, debatieron durante dos largos años de intensas negociaciones y pocos consensos. Para la fracción abolicionista, la trata era indisociable de la prostitución, hasta el punto de que la erradicación de la primera pasaba por la abolición de la segunda, por lo que hacer referencia al 'consentimiento' constituía un oxímoron. Por su parte, el sector proderechos consideró que la presencia de coacción, engaño y uso de la fuerza debían ser las condiciones necesarias para definir la trata, independientemente del fin concreto de explotación y del género de la víctima.

\footnotetext{
${ }^{3}$ Conformada, a su vez, por la Global Alliance Against Traffic in Women (GAATW), International Human Rights Law Group (IHRLG) y la Asian Women's Human Rights Council (AWHRC).
}

Revista del Laboratorio Iberoamericano para el Estudio Sociohistórico de las Sexualidades https://doi.org/10.46661/5020 
Doezema (2005) relata su experiencia durante las negociaciones del Protocolo como trabajadora sexual miembro del HRC que fuese doblemente borrada. En el nivel práctico se trató de una desaparición real. Como en el borrador inicial del Protocolo se vinculaban prostitución y trata, se concretaban medidas contra la inmigración irregular y se limitaba la protección al estatus de víctimas, se opusieron a su participación colectiva como trabajadoras sexuales representantes de la NSWP para no revalidar su contenido, pero decidieron participar a título individual sin filiación para influir en el posicionamiento y evitar tal redacción final. Primera desaparición: las trabajadoras sexuales no estaban como tales durante la negociación. La segunda tuvo lugar en el nivel simbólico correspondiente a la elaboración de la definición de trata. Los esfuerzos del bloque proderechos se dirigieron hacia tratar de evitar la mención específica de la prostitución, queriendo que fuese irrelevante el fin concreto de la explotación para la definición de la trata. Conscientes y experimentadas al respecto de cómo las leyes anti-trata, paradójicamente, vulneran los derechos humanos de las trabajadoras sexuales, buscaron evitar que esta fuese central en la definición a través de una nueva desaparición: no había que darle protagonismo a la prostitución, ellas no estaban allí (aunque sí estuvieran). La CATW batalló duramente por que toda migración que desembocara en el ejercicio de la prostitución fuese configurada como trata, incluso en aquellas situaciones en las que se hubiera consentido el trabajo, el viaje y no mediara el uso de la fuerza ni engaño. Como cada vez resultó más difícil conseguir que no se hiciera referencia explícita a la prostitución, el bloque proderechos ensayó una nueva estrategia discursiva: se puede mencionar siempre y cuando se distinga entre trata y prostitución. En consecuencia, el bloque proderechos tuvo que pasar de argumentar que no se debía mencionar la prostitución a argumentar que esta se podía consentir (Doezema, 2005:79).

La definición resultante no satisfizo a ninguna de las partes. De un lado, el Protocolo se refiere de manera específica a la prostitución ${ }^{4}$. De otro, comprende que el uso de la fuerza y la coacción son centrales para definir la trata, de modo que solo cuando comparezcan los medios comisivos se disuelve el consentimiento y este resultará irrelevante. Con todo, El Protocolo contenía una serie de avances con respecto al viejo Tratado de Lake Success de 1949: reconocía de manera implícita la existencia de la prostitución no forzada; establecía la presencia de coacción como un elemento esencial para definir la trata; y la describía ya no como un atentado contra la dignidad, sino como una violación de los derechos humanos. Y, lo que es más importante, ampliaba la definición de la trata reconociendo otros fines de explotación al margen de la prostitución.

Por tanto, la trata de personas se define, según recoge el artículo 3 (UNODC, 2000:2), como un proceso en el cual han de concurrir tres elementos ${ }^{5}$. El primero de ellos, relativo a la acción, se refiere al «reclutamiento, transporte, transferencia, alojamiento o recepción de personas»; es decir, a la captación, el traslado interno o trasnacional, la acogida y la recepción. El segundo elemento expresa el medio para tal acción, recurrir a «la amenaza, uso de la fuerza u otras formas de coerción, el secuestro, fraude, engaño, abuso de autoridad o de otra situación de vulnerabilidad, o el ofrecimiento o aceptación de pagos o ventajas para obtener el consentimiento de una persona que tenga autoridad sobre otra». Por último, hablaremos de trata, por tanto, cuando tanto medio como acción tengan como fin la explotación: «la explotación comprenderá, como mínimo, la explotación de la prostitución de otras personas u otras formas de explotación sexual, el trabajo o los servicios

\footnotetext{
${ }^{4}$ A pesar del papel protagónico que adquiere la prostitución en el Protocolo, resulta interesante señalar que las situaciones de máxima explotación, en términos de mayor duración, incluso indefinida, de la situación de trata se produzcan, en cambio, en matrimonios forzados (Juliano, 2002:125).

${ }^{5}$ Han de concurrir los tres elementos salvo en el caso de que la víctima sea menor de edad, para quienes el elemento 'medio' se considera irrelevante
}

Revista del Laboratorio Iberoamericano para el Estudio Sociohistórico de las Sexualidades https://doi.org/10.46661/5020 
forzados, la esclavitud o las prácticas análogas a la esclavitud, la servidumbre o la extirpación de órganos».

¿Tenemos realmente una definición ${ }^{6}$ Jordan (2002:32 citada por Doezema 2005:80) señala que precisamente la falta de consenso alcanzado durante de los debates condujo a que términos como 'explotación sexual' y 'explotación de la prostitución ajena' quedaran indeterminados, sin encontrarse suficientemente definidos en el Protocolo ni tampoco en el derecho internacional. El concepto de 'explotación sexual' carece de definición jurídica, de ahí que la OIT recomiende su supresión, dado que se trata de un concepto vago e impreciso, de difícil aplicación, y que, además, «no reconoce el trabajo forzado de las mujeres» (Mujeres con derechos, 2018:2). Quizás el resultado más grave de esta ausencia de acuerdos descansa en que el Protocolo no proporciona un estándar internacional de 'víctima de trata'. En consecuencia, le compete a cada Estado establecer el contenido de este término y aledaños, lo cual solo se entiende si, de nuevo, comprendemos la trata como una categoría lábil, no un objeto natural o autoevidente, donde el discurso, en sentido foucaultiano, construye el objeto. Esta es la razón que explica por qué en países como Argentina o Suecia cualquier mediación de terceros se capture bajo el tipo penal de la trata, sin diferenciarlo de manera suficiente del delito de proxenetismo.

Con todo, la definición del Protocolo no se refiere a un acto concreto, sino a un proceso ( $O^{\prime}$ Connell Davidson, 2014:261), de modo que los tres elementos pueden combinarse de diferentes maneras derivando en acciones y resultados distintos. Además, el Protocolo se enmarca en la Convención contra la Delincuencia Organizada Trasnacional, agrupado junto al Protocolo sobre el tráfico ilegal de inmigrantes. De ahí que:

"incluso si los dilemas conceptuales pudieran resolverse, el Protocolo contra la trata seguiría siendo un instrumento altamente selectivo con el cual abordar el problema general del trabajo forzado, puesto que, al estar enmarcado por la Convención contra la Delincuencia Organizada Trasnacional, solo los delitos migratorios y la actividad de la delincuencia organizada pueden detonar las intervenciones del Protocolo" (O'Conell Davidson, 2014:262).

El Protocolo favorece lo que Yamila Azize (2004) denominó el enfoque trafiquista de las migraciones, la filosofía de la Europa Fortaleza que desde medios de comunicación y agencias internacionales representan a las migraciones como modalidades del tráfico. Asimismo, el trafiquismo enmascara las causas estructurales que lo originan; de acuerdo con Mestre: «una parte de estas redes son redes de tráfico ilícito de seres humanos que engañan y se lucran con la miseria ajena, pero todas las redes y sobre todo su criminalización son consecuencia del cierre de fronteras» (Mestre, 2004:255). El modelo español se enmarca en esta perspectiva, el cual, como señalan diferentes entidades especializadas (Proyecto Esperanza, 2010; Genera y Antígona, 2011), acarrea graves consecuencias para las personas en situación de trata, puesto que privilegia el control migratorio y la causación penal de los tratantes por encima de la garantía de los derechos humanos de las víctimas, que queda en un segundo plano.

\footnotetext{
${ }^{6}$ Por otro lado, Julia O'Connell Davidson (2014:258-259) expone los inconvenientes de expresiones como 'la esclavitud moderna' para definir a la trata de personas. La autora argumenta que asimilar estos crímenes de lesa humanidad vacía en gran medida a la esclavitud de su significado original e histórico; esto es, borra la experiencia específica racial. La esclavitud que sufrió el pueblo negro fue un estatus legal y una condición que se determinaba a partir del nacimiento, de forma permanente, la cual decretaba el derecho a la propiedad de esa persona. Aunque las personas en situación de tratan sufran igualmente la pérdida de control sobre la propia vida, los esclavos no siempre vivieron este control absoluto puesto que, al ser una institución legal, los amos no precisaban controlarles para ejercer poder.
}

Revista del Laboratorio Iberoamericano para el Estudio Sociohistórico de las Sexualidades https://doi.org/10.46661/5020 
La lucha contra la trata y el control migratorio forman parte del mismo entramado, pensemos, por ejemplo, que la identificación de las víctimas de trata suele llevarse a cabo durante los mismos operativos policiales que tienen como prioridad detectar a migrantes irregulares. Así, detrás de las redadas y la cobertura mediática que reza haber liberado a las mujeres, muchas de ellas serán sancionadas por infracciones de la Ley de Extranjería, encausadas por asociación ilícita y falsedad documental (Acién y Checa, 2011:14), y posteriormente expulsadas. Además, la denuncia posee un papel absolutamente central. Tanto la protección como el acceso a derechos se encuentran condicionados a que la mujer en situación de trata decida colaborar con la policía poniendo la denuncia, lo cual, a su vez, supone que cuente con información suficiente y novedosa sobre la red en cuestión, de modo que se descarga sobre ellas todo el proceso penal. Que los derechos dependan de la colaboración, de su utilidad para el proceso judicial que encause el delito, como una suerte de intercambio de favores con la deportación como amenaza si no decide colaborar, evidencia que la prioridad no son sus derechos humanos, sino, de nuevo: el control migratorio y la persecución del delito.

\subsection{La cruzada estadounidense}

El último de nuestros episodios clave da cuenta de cómo logró situarse la interpretación triunfante en la agenda internacional. Este episodio nos traslada a la configuración geopolítica del relato contemporáneo, que abandona la caracterización racista 'de blancas' por el término postcolonial 'de personas' tras la Segunda Guerra Mundial. Si bien las negociaciones de Palermo implicaron tanto a los planos nacionales, trasnacionales (como coaliciones y lobbys) y supranacionales (como las Naciones Unidas) (Piscitelli, 2015), en este epígrafe nos situamos en el contexto estadounidense.

La trata comienza a vislumbrarse como una cuestión política relevante durante el gobierno de Clinton, pero no ocuparía un puesto protagónico hasta el gobierno de la Administración de George W. Bush (Stolz, 2007). Tras las polémicas por la invasión de Irak, Bush trata de restaurar sus apoyos internacionales a través del liderazgo internacional de una causa humanitarita: la trata (Varela, 2014). En 2003 su Departamento de Estado establece el Índice Anual de Trata de Personas (Tip Report) donde clasifica y evalúa a los países en función de sus acciones para prevenir la trata. De esta manera, Estados Unidos se posiciona como el donante principal de los programas internacionales de cooperación contra el VIH (USAID) y los países peor calificados en el Tip Report pueden ver comprometida la ayuda internacional (Ditmore, 2005). A su vez, para que las entidades adscritas puedan acceder a los fondos el gobierno estadounidense deben firmar el 'compromiso antiprostitución' (anti prostitution pledge). Este supone que, para recibir financiación, las entidades han de negarse a colaborar con organizaciones de trabajadoras sexuales, a afirmar la prostitución como trabajo y a oponerse a su legalización (Saunders, 2004; 2005).

Weitzer (2014) ha descrito esta expansión de las políticas estadounidenses a través de la lucha contra la trata en términos de una cruzada moral. Las cruzadas morales, nos dice, se articulan en torno a la lucha contra aquella condición o actividad que se configura como un mal sin reservas. Si bien las cruzadas morales pueden responder a motivaciones humanitarias, también aparejan otros intereses por reforzar las fronteras, las jerarquías y los estándares morales que se perciben en riesgo de resquebrajarse o que amenazan un estilo de vida que se estima deseable. En síntesis, las cruzadas morales reúnen tres características. En primer lugar, sobredimensionan el problema exagerando las cifras por encima de la evidencia disponible (Llobet, 2017:17-20). En segundo lugar, emplean las historias más terribles y extremas como ejemplos paradigmáticos. En tercer lugar, se expresan en la defensa de su descripción de una manera categórica que «existe en la medida exacta en la que ellos los escriben y se niegan a reconocer cualquier escala de grises» (Weitzer, 2014:190).

La expansión de la cruzada tendrá éxito si se encuentra avalada por suficientes grupos con poder e influencia como políticos, personalidades con alto capital simbólico en los movimientos sociales,

Revista del Laboratorio Iberoamericano para el Estudio Sociohistórico de las Sexualidades https://doi.org/10.46661/5020 
medios de comunicación, entidades sin ánimo de lucro y agencias gubernamentales. Como toda lucha simbólica, se trata de una batalla entre las fuerzas del bien contra las del mal, de modo que la cruzada se estructura a partir de una polarización maniquea. Así, quienes muestren matices o reticencias con respecto a la descripción del fenómeno serán tildadas como partidarios del mal: colaboradores, proxenetas o apologistas. Una vez la cruzada alcanza su objetivo principal (este es: capitanear la agenda política del tema en cuestión y forjar su conceptualización como sentido común) disemina su potencial hacia otras cuestiones que asimila y vincula con su impulso principal. Esto que Weitzer (2014:197) denomina como 'expansión de dominio' en el escenario español ha logrado extender y vincular la lucha por la abolición de la prostitución con la lucha por la prohibición de la gestación subrogada ${ }^{7}$, en tanto entienden que ambas cuestiones tienen en común la amenaza contra su bastión moral: la mercantilización del cuerpo.

A través de estos episodios van compareciendo los diferentes elementos que contribuyeron a configurar la interpretación hegemónica sobre la trata. En primer lugar, el trabajo activista en los foros supranacionales colaboró en la reificación del relato de la trata de blancas del siglo XIX al tematizar las vulneraciones de derechos de las mujeres como índices de violencia sexual, en detrimento del resto de finalidades de explotación hacia los cuales se orienta la trata de personas en sentido amplio. En segundo lugar, ante la falta de consensos alcanzados durante los debates de Palermo, el Protocolo solo pudo describirla como un proceso, repleto de indeterminaciones cuyos huecos de significado podrían rellenarse por la anterior preconcepción. Como resultado, si bien carecemos de un estándar internacional unívoco, pasó a enmarcarse en el enfoque trafiquista que privilegia el control migratorio y la irrupción del derecho penal. Finalmente, la cruzada estadounidense terminó por estabilizar la interpretación dominante en la agenda internacional. Esta genealogía al uso da cuenta del trabajo de construcción política y de negociación de significados detrás de un concepto que se asume autoevidente como la trata y, en particular, de su asimilación con la prostitución. Así se entiende que para la producción del concepto 'trata' resulten irrelevantes las especificidades locales, las múltiples desigualdades sociales concretas, y, en cambio, podamos oscilar entre contextos nacionales tan divergentes. A continuación, me centraré en la segunda parte del argumento abolicionista que asume que la criminalización de la demanda reduce la trata

\section{La evidencia empírica de la apuesta sueca y los efectos de la sanción}

El 1 de enero de 1999 entró en vigor en Suecia un nuevo paradigma abolicionista: la Ley de compra de sexo (Sexköpslagen). Junto a las leyes relativas al proxenetismo y a la que prescribe la confiscación de espacios destinados a la prostitución, la novedad legislativa estribaba en la criminalización de los clientes a través de multas o, en su ausencia, penas de hasta un año de prisión. A su vez, Suecia impulsó toda una gama de medidas y protecciones sociales que tienen como objetivo rehabilitar o reinsertar a las prostitutas (Waltman, 2011).

En 2010, el gobierno sueco publicó el resumen en inglés del informe en el que evaluaba el impacto de su modelo (Skarhead, 2010). Su proclamado éxito (Ekberg, 2004) condujo a otros países europeos a implantar el modelo, como Noruega en 2008 o Islandia al año siguiente. Ahora bien, en aquel resumen triunfalista, que seleccionó cuidadosamente los fragmentos a traducir (Jordan, 2012:2), se aseveraba que el modelo había disminuido no solo la prostitución, sino también la trata y que, además, había disuadido a los clientes y modificado las actitudes de la sociedad con relación a la

\footnotetext{
${ }^{7}$ Práctica, sin embargo, ilegal en España. Si bien parece que la posición abolicionista se muestra contraria a esta práctica de manera unánime, desde la posición proderechos encontramos toda la gama de posicionamientos al respecto.
}

Revista del Laboratorio Iberoamericano para el Estudio Sociohistórico de las Sexualidades https://doi.org/10.46661/5020 
prostitución. Este informe ha sido criticado ${ }^{8}$ en primera instancia por su metodología y discutible rigor científico, ya que establecía a priori que los resultados habrían de confirmar la idea de que la compra de sexo tendría que mantenerse en la ilegalidad. Sin embargo, al margen de la ausencia de objetividad, diversas autoras cuestionan la evidencia empírica que sustenta tales afirmaciones (Kulick, 2003, 2005; O'Connell Davidson, 2003; GAATW, 2011; Dodillet y Östergren, 2011; Danna, 2012; Levy y Jakobssson, 2014; Levy, 2015; Amnistía Internacional, 2016).

En primer lugar, respecto a la disminución de la prostitución en sí misma, resulta arriesgado establecer comparativas a tenor de los datos disponibles previos a la entrada en vigor de la Ley. Estos solo contabilizaban la prostitución femenina callejera cisgénero de las tres grandes ciudades suecas y sobre la restante solo podían ofrecer estimaciones (Dodillet y Östergren, 2011:7). De hecho, según las estimaciones del Centro de Conocimiento de Malmoe, que cifra la prostitución de interior o indoors en cuatro quintas partes de la industria actual, Dodillet y Örtergren (2011:9) concluyen comparando las cifras que el número de personas en ejercicio sería similar al de antes de la implantación de la Ley. El mismo Swedish National Board (Jordan, 2012:11) concede que no hay relación de causa-efecto entre la Ley y los cambios visibles de la prostitución. ¿De dónde surge entonces esa afirmación? De la reducción de la prostitución callejera, la más visible. Sin embargo, que la prostitución callejera se reduzca no quiere decir que toda la prostitución lo haga o que desaparezca, sino que, más bien nos llevaría a pensar que se ha desplazado a lugares mejor escondidos. Esta percepción la confirma la policía nacional sueca que señala cómo la prostitución callejera se ha recolocado en hoteles, casas particulares, clubes nocturnos y restaurantes e, incluso, indica que el número de salas de masaje tailandés se ha triplicado en solo tres años (Swedish National Police Board, 2012:13). Lo que el informe sí contempla es el cambio de rostro de la prostitución callejera protagonizada por migrantes (Skarhead, 2010:20), presumiblemente indocumentadas y, como tales, más expuestas a la dependencia de intermediarios y proxenetas, en un claro empeoramiento de sus condiciones (Anders y Rosenberg, 2001; Bernstein, 2007:154-163).

En segundo lugar, respecto a la reducción de la trata, las autoras compilan los datos del Comité de la Policía Nacional que dan cuenta de que los casos de trata denunciados son menores y menores, incluso, las condenas a tratantes, pero dichas cifras no descienden de manera constante, sino que fluctúan cada año. Incluso el informe admite que no hay pruebas fiables en relación con su incidencia en la trata (Skarhead, 2010:35). Con todo, las bajas cifras no son el resultado del modelo nórdico, sino una característica del país sueco: en la Encuesta Nacional sobre Prostitución de 1993 ya se advertía que Suecia no era un país de destino predilecto para la trata con fines de prostitución forzada, un fenómeno minoritario (Heim y Monfort, 2004:118). De acuerdo con López Riopedre «llama bastante la atención que en un país con una población estimada de apenas un millar de trabajadoras sexuales en las calles (Kulick, 2003) se haya optado por abanderar la lucha contra la prostitución a nivel mundial» (2011:13). Por otro lado, la definición de trata que maneja el país nórdico no sigue lo estipulado por el Protocolo de Palermo, ya que, para Suecia, trata es cualquier prostitución que implique terceros (Jordan, 2012:5), sin los medios comisivos del engaño, coacción y uso de la fuerza. Ahora bien, si, como ha ocurrido en Dinamarca y Noruega, lo que se interpreta como un éxito es que las víctimas de trata se dirijan ahora hacia otros países, entonces lo que

\footnotetext{
${ }^{8}$ Dodilet y Östergren (2011) compilaron toda la información procedente de autoridades suecas (Consejo Nacional de Salud y Bienestar, Consejo Nacional para la Prevención del Crimen, Comité de Policía Nacional, el informe de evaluación oficial de 2010 y la respuesta de cincuenta y dos entidades), así como la encuesta sobre prostitución de 1995, la realizada por el Ministerio de Justicia Noruego en 2004, el proyecto de investigación del Instituto Nórdico de Género, la encuesta de 2008 Veme, el informe de 2010 en Malmoe y el informe de 2011 de la Federación sueca LGTB.
}

Revista del Laboratorio Iberoamericano para el Estudio Sociohistórico de las Sexualidades https://doi.org/10.46661/5020 
importa no es el volumen real de la trata con independencia de su destino, sino la higiene de la conciencia nacional acerca de la existencia del fenómeno en sus fronteras.

Otro de los proclamados éxitos del modelo sueco se basa en la afirmación de que la tipificación penal de la compra de sexo ha logrado disuadir ${ }^{9}$ a la clientela. Respecto a esta cuestión, en primer lugar y, de nuevo, no hay datos previos a la Ley con los que establecer comparativas (Jordan, 2012:10) por lo que esta afirmación se apoya en la posibilidad de que así haya sido basándose en encuestas. Sin embargo, la encuesta en la que se asienta se tradujo de manera selectiva, obviando las partes en las que el investigador, Kuosmanen, señalaba que la muestra no era representativa, ni lo suficientemente amplia ni aleatoria, además de que preguntar acerca de una conducta que se encuentra penalizada tiende a sesgar la respuesta del entrevistado. Sobre lo que sí puede disuadir a la clientela es de denunciar casos de proxenetismo y trata para no inculparse (Eriksson, 2008:187) pues, según el Grupo de Expertos en trata del Consejo de Europa, los casos identificados por clientes suponen un 22\% (GRETA, 2004:102).

En cuarto lugar y con relación al cambio en las actitudes de la población, si se analizan las cuatro encuestas en las que se basa el informe para sostener que la población ahora respalda la Ley, lo que se advierte es que apoyan, en realidad, un modelo prohibicionista. Así, la mayor parte de ese $80 \%$ a favor de la criminalización declaró que la mujer también tendría que ser penalizada (Jordan, 2012:15). La investigación de Amnistía Internacional en Noruega encontró la prevalencia de una actitud social semejante a favor del prohibicionismo y que, además, respaldaba el racismo (puta, vete a tu país es una frase comúnmente escuchada por las trabajadoras del informe; Amnistía Internacional, 2016:7). Por tanto, la población no parece haber adquirido una conciencia abolicionista, y es que, extender el mensaje de que la prostitución es mala con facilidad se traduce en la creencia de que las prostitutas son las responsables de ese mal y, por ello, merecen ser castigadas.

Ahora bien, que el proclamado éxito no sea tal y como el abolicionismo difunde no quiere decir que este no pudiese ser un buen modelo. Para valorarlo tendríamos que reparar en los efectos que la sanción de la demanda produce en quienes ejercen la prostitución. Amnistía Internacional concluye, de su estudio en Noruega (2016), que el impacto que la criminalización tiene sobre las trabajadoras sexuales supera con creces las consecuencias a las que se exponen los clientes. Asimismo, la NSWP (2015) replica muchos de los resultados de Amnistía Internacional en Suecia, documentando redadas invasivas y acoso policial durante la detección de clientes, deportaciones de trabajadoras sexuales migrantes, retiradas de la guardia custodia de sus hijos y, puesto que los arrendadores pueden ser acusados de proxenetismo al lucrarse del ejercicio, desalojos de sus viviendas de alquiler.

En el contexto español, 1 de julio de 2015 entró en vigor la Ley Orgánica de Protección de la Seguridad Ciudadana (LO 4/2015, de 30 de marzo de 2015; LOPSC, en adelante) que sanciona, por vía administrativa, un amplio abanico de conductas en el espacio público (Barcons, 2018:97). Con

\footnotetext{
${ }^{9}$ Un experimento realizado por la Radio Nacional Sueca en 2009 apuntó en la dirección inversa, al publicar un anuncio de prostitución falso desde 19 estaciones de radio locales y obtener en menos de una semana 1.000 respuestas por todo el país. Devolvieron la llamada a algunos de los varones y estos respondieron que la prohibición no les disuadía, igual que el límite de velocidad no disuade de la conducción temeraria (Dodillet y Östergren, 2011:13). De hecho, ONUSIDA considera que la disuasión, de producirse, podría limitarse a la de aquellos clientes más respetuosos e incrementar en cambio la proporción de clientes agresivos o peligrosos a quienes no asuste la penalización (UNAIDS, 2009).
}

Revista del Laboratorio Iberoamericano para el Estudio Sociohistórico de las Sexualidades https://doi.org/10.46661/5020 
relación al ejercicio de la prostitución callejera, la LOSPC sanciona de manera explícita ${ }^{10}$ la demanda de prostitución en la vía pública a través del artículo 36.11. Esta es la primera norma de carácter estatal que criminaliza la demanda de prostitución, la cual no modifica ni colisiona con el régimen penal, sino que solo vendría a ampliar el ámbito de aplicación de las ordenanzas municipales desde el nivel local hasta el nacional (Villacampa, 2015:439; Molina Montero, 2018:142).

De nuevo, gran parte de los efectos que se derivan de la criminalización de la clientela inciden en mayor medida en las trabajadoras sexuales (Bodelón y Arce, 2018). Para evitar que las sancionen, tanto a ellas como a sus fuentes de ingresos, las mujeres tienden a ocuparse en lugares alejados y poco iluminados o en horas con menor flujo de patrulleros. Estas maniobras las exponen a un mayor riesgo de sufrir violencia y abusos, merman su seguridad en el trabajo, así como recortan gravemente la capacidad de negociación de las trabajadoras. Pendientes de evitar a la policía, las mujeres disponen de poco tiempo para evaluar y seleccionar al cliente, lo que disminuye su poder a la hora de fijar las prácticas, la tarifa y el uso del preservativo. Además, el descenso de la clientela en la calle da lugar a una lógica bajada de los ingresos y un aumento de la competencia. Si hay menos clientes, las mujeres habrán de bajar las tarifas o filtrar menos; es decir, ocuparse con clientes que antes hubiesen rechazado. Así, la reducción creciente del control sobre sus condiciones de trabajo se agrava por la presión económica. En otras palabras, las trabajadoras negocian atravesadas por una mayor desesperación económica que, paradójicamente, beneficia al cliente. Como los varones consideran que están corriendo el riesgo de ser sancionados, a menudo buscan con esa excusa imponer sus condiciones como no usar preservativo, regatear los precios o, incluso, evitar pagar el servicio.

\section{A modo de conclusión: racionalidades punitivas y derivas neoliberales}

Gran parte del movimiento abolicionista considera que si el derecho actuara de manera más tajante contra la demanda de prostitución tanto esta como la trata progresivamente disminuirían. Este compromiso con el modelo sueco deposita una excesiva confianza en el derecho penal hasta el punto de configurarlo como un medio de impartir justicia. Según la criminóloga Tamar Pitch, los movimientos sociales apelan al derecho penal porque persiguen tres grandes objetivos: 1) porque consideran que previene el problema al disuadir a los victimarios con la amenaza de castigo; 2) por su papel simbólico, que definirá a tal realidad como un mal universalmente reconocido y a los intereses de ese grupo como valores morales protegidos; 3) y como herramienta pedagógica, la cual se espera que modifique las actitudes sociales con relación al problema. Aun cuando las activistas tengan en mente uno solo de estos objetivos «no, obstante, la criminalización implica a los tres» (Pitch, 2003:136).

De un lado, la función preventiva del derecho penal es un asunto hartamente discutido por la criminología crítica que reconoce que ni disuade ni previene ni reinserta (Sánchez Concheiro, 2006), sencillamente, en todo caso, aísla. De otro lado, cabe preguntarse: ¿ puede el sistema penal resolver los problemas sociales?, ¿puede ser empleado por parte del movimiento feminista como un instrumento adecuado para la transformación social? En un sentido fuerte, diversas criminólogas, como Smart (2016) cuestionan que el derecho penal pueda transformar la realidad social y combatir desigualdades como la de género, en la medida en que dicho sistema forma parte del patriarcado mismo (Davis, 2003). En palabras de Audre Lorde (1988:91) «porque las herramientas del amo

\footnotetext{
${ }^{10}$ Dado el objeto del ensayo, me centro solo en los aspectos de la LOPSC que sancionan a la demanda. No obstante, esta Ley también multa, aunque de manera encubierta, a quienes ejercen la prostitución en la vía pública a través de los artículos 36.6 (desobediencia a la autoridad) y 37.5 (exhibición obscena).
}

Revista del Laboratorio Iberoamericano para el Estudio Sociohistórico de las Sexualidades https://doi.org/10.46661/5020 
nunca desarmarán la casa del amo». En un sentido débil, Andrade (1997) argumenta que la capacidad de este instrumento para proteger a las mujeres de la violencia es de naturaleza limitada:

"[...] no previene de nuevas violencias, no escucha los distintos intereses de las víctimas, no contribuye a la comprensión de la propia violencia sexual ni a la gestión del conflicto y, mucho menos, a la transformación de las relaciones de género. En esta crisis se sintetiza lo que vengo denominando «incapacidad preventiva y resolutoria del sistema penal»" (Andrade, 1997:47).

Esta búsqueda creciente de la justicia social a través de la justicia penal y, en consecuencia, la reducción de la primera a la segunda es analizada a menudo por Elizabeth Bernstein. Bernstein (2007b; 2010; 2012) describe el giro carcelario del feminismo abolicionista estadounidense, desde la alianza del llamado movimiento Mayoría Moral hasta las campañas actuales contra la trata. Bernstein (2007b) bautiza al abolicionismo como feminismo punitivista (en la traducción de Iglesias, 2018:15) y señala como factores de cohesión de aquellos extraños compañeros de cama (radicales de izquierda, feministas, conservadores y cristianos evangélicos), tanto la demanda de castigo como el objetivo compartido de un ideal de vida buena, en concreto, de una ética sexual relacional. En el contexto español, la presencia reiterada en coloquios abolicionistas de altos cargos de la policía, el volumen de entidades de asistencia social cristianas y la unión de fuerzas para juzgar al sindicato de trabajadoras sexuales OTRAS frente a la Audiencia Nacional, tribunal dedicado a crímenes contra el terrorismo, aterrizan la caracterización de Bernstein lejos de ser meras abstracciones en acontecimientos consagrados.

Ciertamente, al abolicionismo partidario de la penalización de la clientela pudiera no ser un aliado consciente de los sectores conservadores favorables al punitivismo y a los aparatos y fuerzas represivas del Estado. Sin embargo, estos lazos vienen dados no tanto por los principios que defiendan, que les diferencian, sino por la solución que proponen, que les reúne. De acuerdo con Pitch (2003: 129) para entender cómo se configura un problema social debemos centrarnos, como vía epistémica y metodológica, en la solución que se plantea. En este caso, la demanda de criminalización de la clientela hiperboliza la prostitución como un asunto exclusivo del género y susceptible de ser resuelto a través de instrumentos punitivos. Por ello, aun cuando un sector del abolicionismo apele al derecho penal por sus funciones simbólicas y pedagógicas, estas mismas demandas resultan fácilmente instrumentalizables por sectores conservadores. Citando a Bumiller (2008) Bernstein (2010:56) subraya cómo el abolicionismo es empleado para justificar campañas más amplias de criminalización, ya que sirve a los intereses del control social. Así, le otorga cobertura ideológica tanto al hostigamiento policial a través de ordenanzas municipales y LOPSC en la calle como al cierre de fronteras de la Europa fortaleza mediante el enfoque trafiquista.

Al margen de una concepción punitiva de la justicia social, nos resta por considerar las racionalidades neoliberales que anidan en el mantra discursivo 'sin clientes no hay trata'. A partir de la década de los 70 del siglo pasado, los colectivos feministas españoles advirtieron que la noción de 'opresión sexual' resultaba jurídicamente inoperante. Con el objetivo de que la violencia sexual se reconociera ya no como un atentado contra el honor familiar, sino contra las mujeres, comenzaron a demandar tipificaciones penales y, para ello, tuvieron que desplazar el análisis en clave de opresión por el de victimización (Bodelón, 1998:128). Para permitir la irrupción del derecho, los problemas estructurales tuvieron que configurarse como daños individuales, lo que Pitch (2003) denomina el desplazamiento del asidero ético normativo de la opresión por el de la victimización. En palabras de Bodelón: «Mientras que el concepto de 'opresión' denuncia una situación estructural y hace partícipes del problema a personas no afectadas, el concepto de 'víctima' reduce el problema a un daño individual» (1998:133). Así, cuando el derecho entra en escena las desigualdades sociales, como la de género, fruto de factores estructurales, se convierten en el resultado simple de una serie de acciones concretas e intencionales de un individuo o un grupo de ellos. En consecuencia, la responsabilidad deja de ser sistémica para individualizarse.

Revista del Laboratorio Iberoamericano para el Estudio Sociohistórico de las Sexualidades https://doi.org/10.46661/5020 
La creencia de que la trata se combate criminalizando a la clientela de la prostitución supone que podemos eludir los factores estructurales para centrarnos en la disuasión de los hombres malos. En consecuencia, las deudas coloniales del Sur global; tanto las regulaciones y excepciones fiscales que facilitan el trabajo esclavo como la deslocalización de las fábricas; el cierre de fronteras y la clandestinidad obligatoria en la que se desarrolla la migración laboral; la desregulación creciente del trabajo informal; y la desigualdad no solo de género, sino racial; todo este marco complejo desaparece eximiendo al Norte de su responsabilidad en la creación y en el mantenimiento de las condiciones materiales que producen la trata (GAATW, 2011). Dichos factores estructurales en España se conjugan con las condiciones restrictivas para el acceso al estatus de ciudadanía que impone la normativa de extranjería y sus mecanismos (controles, redadas, internamientos en el CIE y deportaciones) generando un caldo de cultivo que beneficia a las mafias y a las redes que explotan y extorsionan a los migrantes. Cuando estas causas se listan y se reconoce la alianza entre patriarcado, colonialismo, racismo y capital como estructuras responsables de la trata (Cobo, 2017) terminan concurriendo como elementos agregados que favorecen la que vuelve a asumirse como la verdadera causa principal, de nuevo: la existencia de la clientela. La filosofía sueca, de hecho, considera que la receta para salir de la pobreza es apostar por más capitalismo, realizando inyecciones económicas a los países del Sur global sin intervenir en el modo de producción y el nivel de consumo del Norte. El enfoque que culpa en exclusiva al cliente de prostitución de la existencia de la trata mistifica, disculpa y oculta las estructuras económicas, políticas y legales que se encuentran a la base del fenómeno.

En dicha dirección, en el año 2000 el Parlamento Europeo instaba en su informe Nuevas medidas en el ámbito de lucha contra la trata a analizar cómo las políticas migratorias de los Estados miembro favorecían la prevalencia de la trata (Juliano, 2007:30). Por ello, incluso en el hipotético caso de que la criminalización de la clientela de la prostitución consiguiese desalentar la modalidad con fines de prostitución forzada, esto no eliminaría la trata, sino que podría reconducirla hacia otros sectores, lo cual da debida cuenta de que para el debate no es la trata lo que importa, sino la prostitución. Se precisa recuperar los enfoques materiales, en detrimento de los simbólicos, que busquen fortalecer y garantizar los derechos de las personas trabajadoras, legislen por la apertura de fronteras y la organización segura de la migración laboral. Se trata, en suma, de desplazar el punitivismo como objetivo, el control migratorio como método y la ideología como principio para poner en el centro los derechos humanos de las personas en situación de trata, desde la prevención, protección y asistencia integral, con independencia de la modalidad de explotación que hayan sufrido. 


\section{Bibliografía}

Acién González, E. y Checa y Olmos, F. (2011). La actualidad del abordaje de la trata de personas para la prostitución forzada en España. El Plan Integral y sus implicaciones para trabajadoras del sexo inmigradas, Gazeta de Antropología 27/1, artículo 8. En http://www.gazetaantropologia.es/?p=1322. Accedido el 28 de junio de 2020.

Amnistía Internacional (2016). El coste humano de "machacar" el mercado: la penalización del trabajo sexual e Noruega. Resumen ejecutivo. En https://www.amnesty.org/download/Documents/EUR3641302016SPANISH.PDF. Accedido el 28 de junio de 2020.

Anders, N. y Rosenberg, T. (2001). Rapport: Lag (1998: 408) om Förbud mot Köp av Sexuella Tjänster. Metodutveckling Avseende Åtgärder mot Prostitution. Polismyndigheten i Skåne: Malmoe.

Andrade, V. R. Pereira de (1997). Criminologia e feminismo: da mulher como vítima à mulher como sujeito de construção da cidadania, Sequência: estudios jurídicos e políticos 18(35): 42-49.

Azize, Y. (2004). Empujar fronteras: mujeres y migración internacional desde América Latina, 0. Trabajador@s del sexo. Derechos, migraciones y tráfico en el S.XXI. Bellaterra: Barcelona: 167-180.

Barcons Campmajó, M. (2018). Las ordenanzas municipales: entre la regulación y la sanción de la prostitución en España, Revista Crítica Penal y Poder 15: 90-109.

Bernstein, E. (2007). Temporarily yours? Intimacy, Authenticity and the commerce of sex, University of Chicago: Chicago.

Bernstein, E. (2007b). The sexual politics of the 'New Abolitionism', Differences 18(3): 128- 151.

Bernstein, E. (2010). Militarized humanitarianism meets carceral feminism: the politics of sex, rights, and freedom in contemporary antitrafficking campaigns, Signs 36 (1): 45-72.

Bernstein, E. (2012). Carceral politics as gender justice? The 'traffic in women' and neoliberal circuits of crime, sex, and rights, Theory and Society 41(3): 233-259.

Bodelón González, E. (1998). El cuestionamiento de la eficacia del derecho en relación a la protección de los intereses de las mujeres, Delito y Sociedad, revista de ciencias sociales 11-12: 125138.

Bodelón González, E. y Arce Becerra, P. (2018). La reglamentación de la prostitución en los ayuntamientos: una técnica ficticia de seguridad ciudadana, Revista crítica Penal y Poder 15: 71-89.

Boletín Oficial de las Cortes Generales (14 diciembre, 2018). Propuesta No de Ley del Grupo Socialista, relativa a erradicar la prostitución y la trata de mujeres y niñas con fines de explotación sexual. Congreso de los Diputados, Serie D, Número 465. Expediente 162/00904. En http://www.congreso.es/public_oficiales/L12/CONG/BOCG/D/BOCG-12-D-465.PDF. Accedido el 28 de junio de 2020.

Bristow, EJ. (1982). Prostitution and Prejudice: The Jewish Fight against White Slavery 1870-1939, Rowman and Littlefield: Macmillan.

CITCO (2018). Trata de seres humanos en España: Balance estadístico 2013-2017. Madrid: Ministerio del Interior del Gobierno España. En http://www.interior.gob.es/documents/10180/6744515/Balance+20132017+de+Trata+de+Seres+ Humanos+en+España.pdf/1fa3bec6-4f1d-4d65-a6a8-5a6ac84c6b81. Accedido el 28 de junio de 2020.

Cobo Bedia, R. (2017). La prostitución en el corazón del capitalismo. Catarata: Madrid.

Revista del Laboratorio Iberoamericano para el Estudio Sociohistórico de las Sexualidades https://doi.org/10.46661/5020 
Connelly, M. T. (1980) The Response to Prostitution in the Progressive Era, University of North Carolina Press: Chapel Hill NC.

Corbin, A. (1990). Women for Hire: Prostitution and Sexuality in France after 1850, Harvard University Press: Cambridge.

Danna, D. (2012). Client-Only Criminalization in the City of Stockholm: A Local Research on the Application of the "Swedish Model" of Prostitution Policy, Sexuality Research and Social Policy 9(1): 80-93.

Davis, A. (2017 [2003]). ¿Son obsoletas las prisiones? Bocavulvaria: Córdoba.

Ditmore, M. (2005). Trafficking in lives: how ideology shapes policy, K. S. P. Trafficking and prostitution reconsidered: new perspectives on migration, sex work and human rights. Paradigm: Boulder: 107-126.

Dodillet, S. y Östergren, P. (2011). La ley de compra de sexo sueca: éxito proclamado y resultados documentados. Presentada en Taller internacional: despenalización de la prostitución y más allá. Experiencias prácticas y retos. La Haya, 3 y 4 de marzo. En https://www.colectivohetaira.org/wpcontent/uploads/2016/06/Ley-sueca.pdf. Accedido el 28 de junio de 2020.

Doezema, J. (1999). Loose women or lost women? The re-emergence of the myth of White slavery in contemporary discurses of trafficking in women, Gender Issuess 18(1): 23-50.

Doezema, J. (2002). The ideology of trafficking. Presentada en la Work Conference Human Trafficking, Center for Ethics and Value Inquiry, Ghent University. En http://old.nswp.org/sites/nswp.org/files/DOEZEMA-IDEOLOGY.pdf. Accedido el 28 de junio de 2020.

Doezema, J. (2004). ¡A crecer! La infantilización de las mujeres en los debates sobre "tráfico de mujeres", O. Trabajador@s del sexo. Derechos, migraciones y tráfico en el siglo XXI. Bellaterra: Barcelona: 151-163.

Doezema, J. (2005). Now you see her, now you don't: Sex workers and the un trafficking Protocolo Negotiations, Social and Legal Studies 14(1): 61- 89.

Ekberg, G. (2004). The Swedish law that prohibits the purchase of sexual services: Best practices for prevention of prostitution and trafficking in human beings, Violence against Women 10(10): 11871218.

Eriksson, J. (2008). Lo que falla en el modelo sueco, G. B. Los retos de la prostitución. Estigmatización, derechos y respeto. Comares: Granada: 185-189.

Genera, Observatori Desc y Grup Antígona Uab (2011). Análisis socio jurídico de la trata con fines de prostitución forzada: herramientas para una intervención desde una perspectiva de derechos, Genera: Barcelona.

Global Alliance Againts Trafficking in Women (2011). MOVING BEYOND 'SUPPLY AND DEMAND' CATCHPHRASES: Assessing the uses and limitations of demand-based approaches in anti-trafficking. Bangkok: GAATW.

http://www.gaatw.org/publications/MovingBeyond_SupplyandDemand_GAATW2011.pdf. Accedido el 28 de junio de 2020.

Grittner, FK. (1990). White Slavery: Myth, Ideology and American Law. Nueva York y Londres: Garland.

Group of Experts on Action Against Trafficking in Human Beings (GRETA) (2018). Report concerning the implementation of the Council of Europe Convention on Actions against Trafficking in Human

Revista del Laboratorio Iberoamericano para el Estudio Sociohistórico de las Sexualidades https://doi.org/10.46661/5020 
Beings by Spain. Second Evaluation Round. Estrasburgo, 27 de septiembre de 2013. En https://rm.coe.int/greta-2018-7-frg-esp-en/16808b51e0. Accedido el 28 de junio de 2020.

Group of Experts on Action Against Trafficking in Human Beings (GRETA) (2004) Report of the Experts Group of Trafficking in Human Beings, Comisión Europea, Bruselas, 22 de diciembre de 2004. En https://ec.europa.eu/anti-trafficking/sites/antitrafficking/files/report_22_dec_en_1.pdf. Accedido el 28 de junio de 2020.

Guy, D. (1992). White slavery. Citizenship and nationality in Argentina, P. S. Y. Nationalisms and Sexualities. Routledge: Nueva York y Londres: 201-217.

Heim, D. y Monfort Soria, N. (2004). Prostitución y políticas públicas: análisis y perspectivas de un conflicto histórico. Especial referencia a la situación en los Países Bajos y Suecia, Revista catalana de Seguretat Pública 15: 115-125.

Iglesias Skulj, A. (2018). ¿Cómo hacerse la sueca? La criminalización de la demanda de servicios sexuales: la gobernanza de la trata sexual en tiempos de feminismo punitivista, Kula. Antropólogos del Atlántico Sur 17: 11- 24.

Jordan, A. (2012). The Swedish Law to Criminalize Clients: A Failed Experiment in Social Engineering, Issue Paper 4:1-17.

Juliano, D. (2002). La prostitución. El espejo oscuro, Icaira: Barcelona.

Juliano, D. (2007). Sobre trabajos y degradaciones, G. B. La prostitución a debate. Por los derechos de las prostitutas. Talasa: Madrid: 27-32.

Kulick, D. (2003). Sex in the new Europe: The criminalization of clients and Swedish fear of penetration, Anthropological theory 3(2): 199-219.

Levy, J. (2015). Criminalising the Purchase of Sex: Lessons from Sweden, Routledge: Abingdon.

Levy, J. y Jakobsson, P. (2014). Sweden's abolitionist discourse and law: Effects on the dynamics of Swedish sex work and on the lives of Sweden's sex workers, Criminology \& Criminal Justice 14(5): 593-607.

Llobet, M. (2017). ¿Prostitución?: ni sí ni no, sino todo lo contrario. Sesgos empíricos, contradicciones de lege lata y desaciertos de lege ferenda, Revista electrónica de ciencia penal y criminología 19: 1-34.

López Riopedre, J. (2011). La criminalización de la industria del sexo, una apuesta políticamente correcta, Gazeta de Antropología http://www.ugr.es/ pwlac/G27_24Jose_Lopez_Riopedre.html. Accedido el 28 de junio de 2020.

Lorde, A. (1988). Las herramientas del amo nunca desarmarán la casa del amo. Este puente, mi espalda. Voces de mujeres tercermundistas en los Estados Unidos. Ism Press: San Francisco: 89-93.

Mestre, R. (2004). Las caras de la prostitución en el Estado español: entre la Ley de Extranjería y el Código Penal.Trabajador@s del sexo: derechos, migraciones y tráfico en el siglo XXI. Bellaterra: Barcelona: 245-262.

Miller, A. M. (2004). Sexuality, Violence against Women, and Human Rights: Women Make Demands and Ladies Get Protection, Health and Human Rights 7(2):16-47.

Ministerio de Sanidad, Servicios Sociales e Igualdad (2018). Plan Integral de lucha contra la trata de mujeres y niñas con fines de explotación sexual (2015-2018). Madrid: Delegación del Gobierno para la Violencia de Género.

http://www.violenciagenero.igualdad.mpr.gob.es/planActuacion/planContraExplotacionSexual/do cs/Plan_Integral_Trata_18_Septiembre2015_2018.pdf. Accedido el 28 de junio de 2020.

Revista del Laboratorio Iberoamericano para el Estudio Sociohistórico de las Sexualidades https://doi.org/10.46661/5020 
Molina Montero, A. (2018). El régimen jurídico de la prostitución y sus diferentes modelos ideológicos, Revista Crítica Penal y Poder 15: 130-149.

Mujeres con Derechos (2018). Articulación feminista por los derechos de las mujeres en situación de trata con fines de prostitución forzada. En http://mujeresconderechos.net/wpcontent/uploads/2018/10/Articulación-feminista-por-los-derechos-de-las-mujeres-contra-latrata.pdf. Accedido el 28 de junio de 2020.

O'Connell Davidson, J. (2003). Sleeping with the enemy? Some problems with feminist abolitionist calls to penalise those who buy commercial sex, Social Policy and Society 2(1): 55-63.

O'Connell Davidson, J. (2014). ¿Podría la verdadera esclava sexual dar un paso adelante?, Debate feminista 50: 256- 279.

Organización Internacional del Trabajo (2012). Estimación mundial sobre el trabajo forzoso. Resumen ejecutivo. En https://www.ilo.org/wcmsp5/groups/public/---ed_norm/--declaration/documents/publication/wcms_182010.pdf. Accedido el 28 de junio de 2020.

Piscitelli, A. (2015). Riesgos: la capilarización del enfrentamiento a la trata de personas en las tensiones entre planos supranacionales, nacionales y locales. Ponencia presentada en el IV Congreso latinoamericano sobre trata y tráfico de personas, Bolivia.

Pitch, T. (2003). ¿Mejor los jinetes que los caballos? El uso del potencial simbólico de la justicia penal por parte de los actores en conflicto. Responsabilidades limitadas. Actores, conflictos y justicia penal. Ad-hoc: Buenos Aires: 125-159.

Proyecto Esperanza (2010). Valoración del nuevo marco jurídico contra la trata de seres humanos. Análisis de casos reales y recomendaciones. Madrid. En https://www.proyectoesperanza.org/wpcontent/uploads/2019/05/2010_Informe_Nuevo_Marco_Jur\%C3\%ADdico_Trata.pdf. Accedido el 28 de junio de 2020.

Rubin, G. (2011). The Trouble with Trafficking. Afterthoughts on 'The Traffic in Women, R. Deviations: A Gayle Rubin Reader. Duke University Press: Durham: 66-88.

Sánchez Concheiro, M. T. (2006). Para acabar con la prisión. La mediación en el Derecho Penal. Justicia de proximidad. Icaria: Barcelona.

Saunders, P. (2004). Prohibiting Sex Work Projects, Restricting Women's Rights: the International Impact of the 2003 U.S. Global aids Act, Sexuality, Human Rights and Health 7(2): 179-192.

Saunders, P. (2005). Traffic violations: determining the meaning of violence in sexual trafficking versus sexwork, Journal of Interpersonal Violence 20(3): 343-360.

Skarhead, A. (2010). Selected extracts of the Swedish government report SOU 2010:49. The Ban against the Purchase of Sexual Services: An evaluation 1999-2008. Swedish Institute: Estocolmo.

Smart, C. (2016). La búsqueda una criminología crítica del derecho, Delito y Sociedad 11-12: 105124.

Stolz, A. (2007). Interpreting the U.S. Human Trafficking Debate Through the Lens of Symbolic Politics, Law \& Policy 29(3): 311-338.

Swedish National Police Board (2012). Trafficking in human beings for sexual and other purposes. Situation Report 13.

https://www.justice.gov.il/Units/Trafficking/MainDocs/swedishnatiolpolice2012trafficking\%20rep ort.pdf. Acceso el 28 de junio de 2020.

Revista del Laboratorio Iberoamericano para el Estudio Sociohistórico de las Sexualidades https://doi.org/10.46661/5020 
Unaids (2009). UNAIDS Guidance Note on HIV and Sex Work. Ginebra: UNAIDS. En https://www.unaids.org/sites/default/files/sub_landing/files/JC2306_UNAIDS-guidance-note-HIVsex-work_en.pdf. Accedido el 28 de junio de 2020.

United States of America Department of State (2010). Trafficking in Persons Report. 10th Edition. En https://2009-2017.state.gov/documents/organization/142979.pdf. Accedido el 28 de junio de 2020.

Unodc (2000). Protocolo para prevenir, reprimir y sancionar la trata de personas especialmente mujeres y niñas y que complementa la Convención de las Naciones Unidas contra la Delincuencia Organizada Trasnacional. Nueva $\quad$ York. En https://www.ohchr.org/Documents/ProfessionalInterest/ProtocolTraffickingInPersons_sp.pdf. Accedido el 28 de junio de 2020.

Vance, C. (1989). Placer y peligro: explorando la sexualidad femenina, Talasa: Madrid.

Varela, C. (2014). La campaña anti-trata en la Argentina y la agenda supranacional. Género y violencia en el mercado del sexo. Buenos Aires: Biblos: Buenos Aires: 109-149.

Villacampa Estiarte, C. (2015). A vueltas con la prostitución callejera: ¿Hemos abandonado definitivamente el prohibicionismo suave?, Estudios Penales y Criminológicos 35: 413-455.

Walkowitz, J. (1980). Prostitution and Victorian Society, Cambridge: Cambridge.

Waltman, M. (2011). Sweden's prohibition of purchase of sex: The law's reasons, impact, and potential, Women's Studies International Forum 34: 449-479.

Weitzer, R. (2014). El Movimiento para Criminalizar el Trabajo Sexual en los Estados Unidos, Debate Feminista 50: 189-219.

Yuval-Davis, N. (1997). Gender and Nation, Sage Publications: Londres. 